Braz J Med Biol Res, October 2011, Volume 44(10) 966-972

doi: 10.1590/S0100-879X2011007500107

Effect of high-fat diets on body composition, lipid metabolism and insulin sensitivity, and the role of exercise on these parameters

D.F. Coelho, L.O. Pereira-Lancha, D.S. Chaves, D. Diwan, R. Ferraz, P.L. Campos-Ferraz, J.R. Poortmans and A.H. Lancha Junior

The Brazilian Journal of Medical and Biological Research is partially financed by

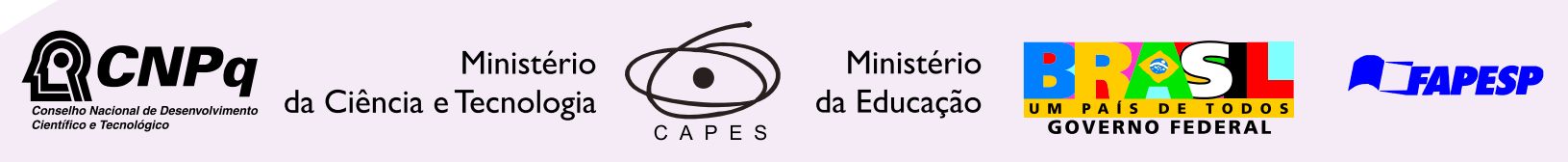

Institutional Sponsors
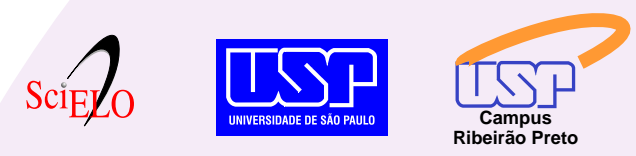

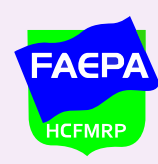

Ф SHIMADZU

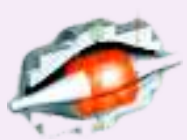

Explore High - Performance MS Orbitrap Technology In Proteomics \& Metabolomics

$\underset{\text { analitica }}{\text { analiticaweb.com.br }}$ SCIENTIFIC 


\title{
Effect of high-fat diets on body composition, lipid metabolism and insulin sensitivity, and the role of exercise on these parameters
}

\author{
D.F. Coelho ${ }^{1,2}$, L.O. Pereira-Lancha ${ }^{2}$, D.S. Chaves $^{2}$, D. Diwan ${ }^{2}$, R. Ferraz ${ }^{2}$, \\ P.L. Campos-Ferraz ${ }^{2}$, J.R. Poortmans ${ }^{3}$ and A.H. Lancha Junior ${ }^{1,2}$ \\ ${ }^{1}$ Departamento de Biologia Celular e Desenvolvimento, Instituto de Ciências Biomédicas, \\ 2Laboratório de Nutrição e Metabolismo Aplicados à Atividade Motora, Escola de Educação Física e Esporte, \\ Universidade de São Paulo, São Paulo, SP, Brasil \\ ${ }^{3}$ Laboratory of Applied Nutrition to Exercise, Free University of Brussels, Brussels, Belgium
}

\begin{abstract}
Dietary fat composition can interfere in the development of obesity due to the specific roles of some fatty acids that have different metabolic activities, which can alter both fat oxidation and deposition rates, resulting in changes in body weight and/or composition. High-fat diets in general are associated with hyperphagia, but the type of dietary fat seems to be more important since saturated fats are linked to a positive fat balance and omental adipose tissue accumulation when compared to other types of fat, while polyunsaturated fats, omega- 3 and omega-6, seem to increase energy expenditure and decrease energy intake by specific mechanisms involving hormone-sensitive lipase, activation of peroxisome proliferator-activated receptor $\alpha(P P A R \alpha)$ and others. Saturated fat intake can also impair insulin sensitivity compared to omega-3 fat, which has the opposite effect due to alterations in cell membranes. Obesity is also associated with impaired mitochondrial function. Fat excess favors the production of malonyl-CoA, which reduces GLUT4 efficiency. The tricarboxylic acid cycle and beta-oxidation are temporarily uncoupled, forming metabolite byproducts that augment reactive oxygen species production. Exercise can restore mitochondrial function and insulin sensitivity, which may be crucial for a better prognosis in treating or preventing obesity.
\end{abstract}

Key words: Fat; Obesity; Insulin; PUFA; Diet; Exercise

\section{Introduction}

Ever since health complications caused by obesity were demonstrated, many studies have been conducted in order to identify the main factors that contribute to its development. The role of genetics in the etiology of obesity has also been extensively investigated.

The identification and sequence of the ob gene, which encodes the peptide leptin, and the finding that a lack of this gene seems to be the main cause of obesity in ob/ob rats (1) have raised interest in obesity genetics. However, the rapid increase in obesity prevalence during the last 20 years cannot be justified by genetic alterations that, theoretically, could not have occurred within such a short period of time (2). Thus, some investigators emphasize that the difference in the prevalence of obesity in some population groups is related to environmental factors, especially diet and reduction of physical activity (3). These aspects, interacting or not with genetic factors, could explain at least in part the excess body fat observed in large proportions worldwide.

High-fat diets are known to lead to a positive fat balance and consequently to adipose mass accumulation $(4,5)$; also, these diets do not seem to stimulate fat oxidation rate in the same way in obese and lean subjects (6). In addition, the type of dietary fat also seems to be a determinant in body fat increase. For example, diets rich in saturated lipids can increase body fat stores to a greater extent when compared to omega-6- and omega-3-rich diets (7). On the other hand, aerobic exercise training improves body composition, aerobic fitness, leptinemia, intramuscular lipid accumulation, and insulin sensitivity in obese individuals (8). However, few studies relate the possible interactions of different types of dietary fat and

Correspondence: D.F. Coelho, Departamento de Biologia Celular e Desenvolvimento, ICB, USP, Av. Prof Mello Moraes, 65, 05508-039 São Paulo, SP, Brasil. E-mail: decoelho@usp.br

Received February 19, 2011. Accepted August 10, 2011. Available online August 26, 2011. Published October 10, 2011. 
exercise. The objective of this review is to connect the interactions of dietary fat, different fatty acids and exercise to metabolic parameters normally impaired in obesity.

\section{The role of high-fat diets in obesity}

An excess of body fat tissue may be related not only to energy intake and energy expenditure in humans, as stated by Flatt (4) and others (9), but also to the type of diet, especially high-fat diets (HFD), which may lead to various metabolic alterations such as hyperphagia in humans (6), reduced lipolytic activity in fat tissue, reduction in leptin secretion and/or sensitivity, hypothalamic neuron apoptosis (10), impairment of mitochondrial metabolism (11), insulin resistance, and obesity (12).

The balance of each nutrient seems to involve a rigorous control to adjust its intake to its oxidation. An increase in carbohydrate and/or protein consumption is accompanied by increased oxidation rates of both nutrients (13). On the other hand, the balance between fat consumption and oxidation rates is not so tightly regulated (13) and depends on the type of fatty acids (7). More details about fatty acids (FA) and fat metabolism are explored below.

\section{Dietary fatty acids and body composition}

Although obesity is associated with HFD, studies have indicated a possible "anti-obesity" effect attributed to polyunsaturated fatty acids (PUFA), particularly to omega-3 docosahexaenoic acid (DHA, C22:6, n-3) and eicosapentaenoic acid (EPA, C20:5, n-3). This may be due to their greater oxidative rates when compared to saturated fatty acids (SFA) (14). Several investigators have shown that FA oxidation increases directly with a concomitant increase in PUFA/SFA intake (15).

Rats submitted to a high saturated fat (HSF) diet for 7 weeks (58\% total caloric intake) developed greater adiposity when compared to a high-omega 3 diet. Surprisingly, the omega 3 group also showed a significant decrease in adiposity when compared to the control low-fat diet $-10 \%$ of total energy intake (7). This indicates that the composition of fat in the diet is more important than the amount of fat.

Animal studies have pointed out that, after intestinal absorption, monounsaturated fatty acids (MUFA) and PUFA produced a higher thermogenic effect (16) and higher oxygen consumption (17) when compared to SFA. However, when PUFA were added to a high-MUFA diet (high PUFA/SFA ratio) for 8 weeks, the expression and activity of hormone-sensitive lipase (HSL) was upregulated and adipose tissue peroxisome proliferatoractivated gamma (PPARY) was reduced when compared to a high-MUFA diet, which significantly elevated de novo hepatic lipogenesis (18). Studies comparing the effects of safflower oil (omega 6 FA) versus beef tallow (SFA) in rats reported that the latter group had a higher fat content in the carcass, decreased sympathetic activity and a lower thermogenic effect (19).

In a recent investigation, Oosterveer et al. (20) studied C57BL/6J mice fed regular chow, a high-fat or an n-3 PUFAenriched high-fat diet using an approach based on mass isotopomer distribution analysis (MIDA) following ${ }^{1-(13)} \mathrm{C}$ acetate infusion in order to determine de novo lipogenesis, fatty acid elongation and cholesterol synthesis. The HFD led to increased hepatic elongation of unlabeled palmitate rather than elongation of de novo synthesized palmitate, and the partial replacement of saturated fat with fish oil completely reversed the lipogenic effects of the HFD, therefore preventing diet-induced hepatic steatosis.

Increased omega-3 PUFA (DHA and EPA) consumption by Wistar rats resulted in reduced visceral adipose tissue content when compared to a group fed higher amounts of SFA (21). The possible mechanisms involved in the increased adiposity due to SFA consumption are listed below.

Altered affinities of $\beta$-adrenergic receptors in brown adipose tissue in heart and soleus muscle (22); lower activity of hormone-sensitive lipase (23); a reduction of sympathetic activity in brown adipose tissue, heart and skeletal muscle (16); lower activity of carnitinepalmitoyl transferase complex (CPT-1) and consequently $\beta$-oxidation in brown adipose tissue (24); increased expression of transcriptional factors such as PPARY and genes involved in adipogenesis (12).

While SFA play a negative role in body composition, unsaturated fatty acids seem to have the opposite effect through the following mechanisms: decreased energy intake and/or increased energy expenditure through the activation of mitochondrial uncoupling proteins (19); reduced lipid uptake by white adipocytes by suppression of lipoprotein lipase (25); increased lipid catabolism enhancing FA oxidation ( $\beta$-oxidation) (25); decreased triacylglycerol synthesis through inhibition of enzymes such as fatty acid synthase (FAS) and stearoyl-CoA desaturase-1 (26); decreased expression of transcriptional factors and genes involved in adipose tissue metabolism (18); PPARs are transcriptional factors of the nuclear receptors family, with a key role in controlling lipid metabolism, adipocyte differentiation and lipid storage. There are two important classes of PPARs: PPARa and PPARy. PPARa activation is involved in hepatic metabolism, FA oxidation in skeletal muscle (27), and in lipoprotein metabolism by improving the concentration of triacylglycerols (TAGs), high-density lipoprotein cholesterol (HDL-C) and the atherogenic lipid profile, while modulating inflammation and insulin resistance (28). PPARy is involved in the proliferation and differentiation of adipocytes, promoting the apoptosis of old and big adipocytes (generally with low insulin sensitivity and high lipolytic rates) and the differentiation of new adipocytes (28). It is up-regulated 
by SFA, which could lead to increased adiposity. This result was demonstrated in an experiment conducted by Yeop et al. (29). These investigators also analyzed some inflammatory factors such as nuclear factor- $\kappa B$ and monocyte chemotactic protein-1 and observed that SFA increased their expression while a PUFA diet (EPA and DHA) repressed them.

PUFA, especially EPA and DHA, act as activators of PPARa (30) in liver and skeletal muscle, an action that could lead to body weight reduction and hypoglycemic effects, respectively (31).

\section{Dietary fatty acid and lipid metabolism}

While elevated plasma HDL-C levels have been associated with a reduction in cardiovascular risk, dietary fish oils rich in omega-3 PUFA may counteract their effect. Morgado et al. (32) studied the effects of different types of fat on lipid metabolism. Male rats were fed a semisynthetic diet containing fish oil (omega-3), sunflower oil (omega-6), olive oil (omega-9), or coconut oil (saturated medium chain triglycerides). Compared to the other diets, omega-3 PUFAs significantly changed the omega-3/ omega- 6 fatty acid ratio of the hepatic membranes, caused a reduction of plasma total and $\mathrm{HDL}-\mathrm{C}$, and selectively increased biliary cholesterol secretion.

Similar results were also obtained by RoklingAndersen et al. (21) who demonstrated that a diet rich in omega-3 PUFA (DHA and EPA) reduced triglycerides, phospholipids and cholesterol when compared to an SFA group. A review study conducted by Siri-Tarino et al. (25) reported that the replacement of SFA with PUFA or MUFA reduces both low-density lipoprotein cholesterol (LDL-C) and HDL-C.

Montoya et al. (33) studied the effects of different fatty acids on lipid metabolism in men and women. They offered four different types of diets containing 35\% fat: saturated diet (palm oil), monounsaturated fat (olive oil), n-6 polyunsaturated fat diet (sunflower oil), and an n-3 polyunsaturated fat diet (sunflower oil supplemented with fish oil). The monounsaturated and polyunsaturated fat diets resulted in a better lipid profile.

Binkoski et al. (34) conducted a 4-week crossover study on men and women with moderate hypercholesterolemia to evaluate the effects of a PUFA diet on lipid and lipoprotein levels and oxidative stress. The PUFA diet decreased both total cholesterol and LDL-C levels compared to the average American diet and the olive oil diet. Total cholesterol decreased by $4.7 \%$ and LDL-C decreased by $5.8 \%$ with the NuSun sunflower oil diet vs the average American diet. PUFA appeared to account for the greater reduction of total and LDL-C and of lag time for LDL oxidation obtained with the NuSun sunflower oil diet. The authors suggested that since PUFAs are important for cholesterol lowering, foods that replace saturated fatty acids should include a balance of unsaturated fatty acids.

\section{Fatty acid intake and insulin sensitivity}

Different types of fatty acids may lead to altered insulin sensitivity. Animal studies have indicated that insulin sensitivity is impaired by SFA intake and is improved by omega-3 FA (25). A possible mechanism may be the reduction of adiponectin secretion, which leads to impaired insulin signaling pathways and prevention of adipose tissue inflammation, respectively (35).

When comparing SFA and MUFA diets in insulinresistant individuals, Paniagua et al. (36) found that a MUFA diet improved insulin resistance (HOMA index) and fasting proinsulin levels. Furthermore, an olive oil-based meal decreased postprandial glucose and insulin concentrations and increased HDL-C and GLP-1 concentrations compared to a carbohydrate-rich diet. In a study conducted by Jenkins et al. (37) the effect of MUFA content was determined in 24 patients with hyperlipidemia. The patients were divided into two groups, high and low MUFA, and after one month it was observed that the high MUFA diet increased HDL-C by $12 \%$. This is very interesting since some PUFA studies have shown that PUFA-rich diets may decrease HDL-C.

It is known that the composition of FA intake could influence the characteristics of cell membranes and their FA components. Changes in the FA composition of the sarcolemma could modify membrane fluidity and stiffness (38). Because of the complexity of the cell membrane, the efficiency of the signal transduction is strongly dependent on the orientation and position of many proteins and the FA composition may play a very important role in the transduction of the insulinemic signal (39).

\section{Influence of dietary fat composition on the development of insulin resistance in both humans and rats}

According to Unger and Scherer (40), insulin resistance in humans can be linked to a gluttonous and slothful lifestyle and can be viewed more as a consequence than as a cause of lipid deposition in a caloric surplus. Thus, calories in excess can lead to hyperinsulinemia, which augments sterol regulatory element-binding protein1c (SREBP-1c) expression in beta cells, resulting in increased lipogenesis and obesity. This effect can be noticed early in life, since during pregnancy maternal obesity, maternal diabetes and increase in nutrients supply for the fetus can increase the risk of obesity in postnatal life (41).

Some but not all dietary fats lead to insulin resistance in rats. Studies on animals and humans have shown that membranes composed mainly of SFA are associated with 
insulin resistance, whereas membranes with a major part of unsaturated fatty acid have a protective role (42). In a study on healthy individuals, insulinemia was higher in those submitted to SFA-rich diets compared to PUFA-rich diets (43). However, Storlien et al. (44) showed that diets high in saturated, monounsaturated (omega-9), or polyunsaturated (omega-6) FA led to severe insulin resistance when compared to a control group and that omega- 3 was able to completely prevent the insulin resistance induced by a saturated-fat diet.

The same authors (45), years later, reported that saturated and trans-unsaturated fatty acids significantly increase insulin resistance, whereas polyunsaturated n-3 fatty acids improve it. They suggested that one possible mechanism is an inefficient molecular signal transduction on the cell membranes induced by dietary fatty acid. In fact, obese patients or patients with type 2 diabetes mellitus display a different FA composition of serum lipids compared to lean subjects, with a higher proportion of the saturated fat palmitate and lower concentrations of linoleic acid, an omega-6 FA (39), which may lead to large amounts of these FA on the cell membrane.

Regarding glucose transporters, high-fat diets decrease gene expression of glucose transporters (GLUT1 and GLUT4) in adipose and muscle tissues. This reduction is attenuated when the FA composition of the diet is changed to a high n-3-PUFA content (46).

PUFA, mainly EPA and DHA, provide an increase in membrane fluidity, number of insulin receptors and also improve insulin action (47). Studies have revealed that individuals submitted to PUFA-rich diets presented fewer alterations of glucose metabolism and lower rates of type 2 diabetes mellitus (48) However, when the fat content was mainly SFA a diminished glucose tolerance was observed (49).

\section{Role of exercise in improving weight loss, mitochondrial function and insulin sensitivity in obese subjects}

Although the fat tissue mass seems to be well controlled by an unconscious and powerful biological system (e.g., weight gain leads to a greater desire to eat), body weight can be reduced by a lower food intake associated with a higher energy expenditure, at least in a motivated individual (50).

Aerobic exercise has been used in weight loss programs for a long time. A study conducted in 1998 by Sial et al. (51) evaluated the role of aerobic physical activity in fat oxidation in sedentary obese individuals submitted to a 16-week exercise program. Before starting the program, fat oxidation was measured in the first minute of exercise and the value obtained was reduced by $50 \%$ after 4 months of exercise. However, fat oxidation after the first $10 \mathrm{~min}$ of exercise was doubled in the exercised group compared to the sedentary individuals, and was higher until the end of exercise (60 $\mathrm{min}$ ).

Aerobic exercise and its muscle adaptations in obese subjects are not only important for weight loss but also for preventing weight regain. The 2009 ACSM position (52) recommends 250 to $300 \mathrm{~min} /$ exercise per week (mostly aerobic). In a longitudinal study, Jakicic et al. (53) observed that obese women who performed less than $150 \mathrm{~min} /$ week of aerobic exercise for 6 months lost $50 \%$ less weight than their counterparts who exercised more than $250 \mathrm{~min} /$ week $(6.5 \times 13 \mathrm{~kg}$, respectively). After 6 additional months of physical training, the group submitted to $150 \mathrm{~min} /$ week gained weight while the other group who exercised for $250 \mathrm{~min} /$ week kept losing weight. In this case, regular and long-lasting exercise probably drastically reduces the hunger pain and desire to eat in these individuals after a calorie-restricted weight loss due to profound effects on energy balance, fuel utilization, lipid accretion, and peripheral homeostatic signals (54).

It is known that increased mitochondrial capacity in endurance-trained athletes augments intramyocellular lipids and also fat oxidation capacity, which could reduce accumulation of byproduct metabolites associated with insulin resistance (55).

Boss et al. (56) studied the effects of $n-3$ and $n-9$ unsaturated fatty acids and exercise on 16 male subjects in an attempt to improve exercise performance, insulin sensitivity and fat oxidation. They used an isoenergetic diet enriched with fish and olive oils containing $34 \%$ fat (12\% SFA, 12\% MUFA, 5\% PUFA) and an exercise protocol consisting of a 10-day gradual endurance training protocol ( $80 \% \mathrm{VO}_{2}$ max). Training significantly increased time to exhaustion and improved insulin sensitivity. Those effects, however, were of similar magnitude in the unsaturated fat group and in controls. However, fat oxidation tended to increase in the unsaturated fat group, but not in controls.

Aerobic exercise increases the formation of free radicals and several studies have shown higher production of thiobarbituric acid-reactive substances, which indicates increased lipid peroxidation (57). Oxidizability of lipids varies linearly with the extent of their unsaturation. Mataix et al. (57) studied the ability of diet and exercise to prevent free radical-mediated damages in lipid peroxidation. They reported that sedentary animals fed a high-MUFA diet showed a higher protection of their mitochondrial membranes against lipid peroxidation than animals fed PUFA. Trained rats showed higher hydroperoxide contents than sedentary animals, and exhaustive effort enhanced the aforementioned results as well as in vitro peroxidation with a free radical inducer.

According to Rogge (58), in obese subjects, mitochondrial functions may be impaired as a result of an improper cellular energy production. This is shown by various metabolic anomalies such as reduced fat oxidation 
and higher reliance on carbohydrate (glucose) for ATP synthesis, ectopic accumulation of fat in muscles, liver, etc., and low basal ATP concentration.

The excess of fat in the cell reduces tricarboxylic acid (TCA) cycle activity and fat oxidation and augments fatty acid synthesis (Figure 1) forming fatty acyl-CoA and malonyl-CoA. Malonyl-CoA inhibits fat transport to the mitochondria (mitochondria overload) and the lack of citrate reduces TCA cycle activity. In the cytosol, betaoxidation flux becomes higher than TCA cycle activity, leading to byproduct accumulation (reactive oxygen species and Ser kinases) that impairs GLUT4 glucose transporter. This action also occurs due to excess fatty
acyl-CoA (59). Exercise and a specific fatty acids supply (EPA and DHA) can reverse this process, reestablishing the coordination between TCA cycle and beta-oxidation, coupling ligand-induced PPAR activity and the metabolic pathways of peroxisome proliferator-activated receptor Y-coactivator-1a (Figure 1).

\section{Conclusion}

High-fat diets could lead to changes in adipose tissue deposition (adiposity), in mitochondrial functions and in insulin sensitivity. These alterations seem to be very important in the etiology of obesity. Also, it is important

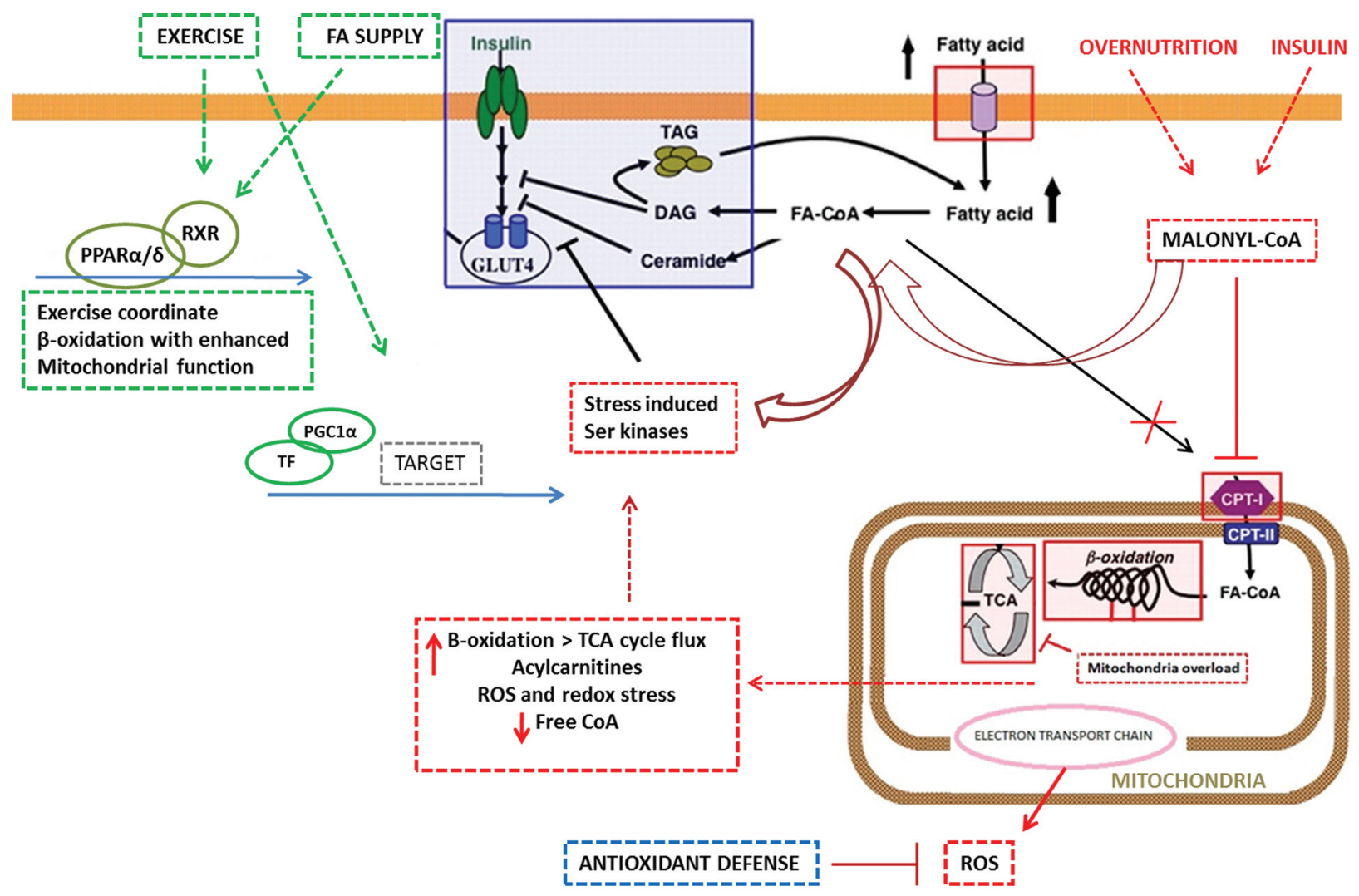

Figure 1. Relationship between exercise, fat and impaired fat metabolism. During conditions of overnutrition there is an increase in fatty acid influx and activation of target genes (mediated by peroxisome proliferator-activated receptor, PPAR), which promote oxidation without an increase in the tricarboxylic acid (TCA) cycle flux. Incomplete fat oxidation results in metabolic byproducts such as acylcarnitines and reactive oxygen species (ROS), which accumulate in the mitochondria. This might activate Ser kinases that impair insulin signaling and GLUT4 (glucose transporter 4) translocation. Impaired mitochondrial energy production, a condition associated with obesity and impaired glucose tolerance, is a situation in which mitochondrial $\beta$-oxidation is decreased in skeletal muscle cells. The activity of carnitine palmitoyltransferase 1 (CPT-1) is inhibited, leading to the accumulation of fatty acyl-CoA within the cytosol. Unmetabolized fatty acyl-CoA (FA-CoA) is then converted to malonyl-CoA and directed to the synthesis of fatty acids, which can accumulate within the cell or be transported to other tissues as triglycerides. Exercise alleviates lipid stress by increasing TCA cycle flux and by coupling ligand-induced PPAR activity with PGC1-mediated remodeling of downstream metabolic pathways, leading to enhanced mitochondrial performance in restoring insulin sensitivity. PGC1 = peroxisome proliferator-activated receptor gamma coactivator; RXR $=$ retinoid $\mathrm{X}$ receptor; $\mathrm{DAG}=$ diacyglycerol; $\mathrm{TAG}=$ triacylglycerol; TF = transcription factor; FA = fatty acids. Modified from Rogge (58), Kraegen et al. (59), and Muoio and Newgard (60). 
to consider the positive effects of exercise on adipose tissue metabolism and to understand the mechanisms by which this tissue affects the kinetics of other macromolecules. Exercise and the consumption of higher amounts of unsaturated fats (MUFA and PUFA) are of primordial importance in the treatment of obesity. Perhaps these two aspects represent the link between genotypic and

\section{References}

1. Zhang Y, Proenca R, Maffei M, Barone M, Leopold L, Friedman JM. Positional cloning of the mouse obese gene and its human homologue. Nature 1994; 372: 425-432.

2. Hill JO, Peters JC. Environmental contributions to the obesity epidemic. Science 1998; 280: 1371-1374

3. WHO (World Health Organization). Diet, nutrition, and the prevention of chronic diseases. Report of a WHO study group. WHO Technical Report Series, Vol. 797: 1-204; 1990.

4. Flatt JP. Use and storage of carbohydrate and fat. Am J Clin Nutr 1995; 61: 952S-959S.

5. Flatt JP, Ravussin E, Acheson KJ, Jequier E. Effects of dietary fat on postprandial substrate oxidation and on carbohydrate and fat balances. J Clin Invest 1985; 76: 1019-1024.

6. Westerterp KR, Smeets A, Lejeune MP, Wouters-Adriaens MP, Westerterp-Plantenga MS. Dietary fat oxidation as a function of body fat. Am J Clin Nutr 2008; 87: 132-135.

7. Wang $\mathrm{H}$, Storlien LH, Huang XF. Effects of dietary fat types on body fatness, leptin, and ARC leptin receptor, NPY, and AgRP mRNA expression. Am J Physiol Endocrinol Metab 2002; 282: E1352-E1359.

8. Solomon TP, Sistrun SN, Krishnan RK, Del Aguila LF, Marchetti CM, O'Carroll SM, et al. Exercise and diet enhance fat oxidation and reduce insulin resistance in older obese adults. J Appl Physiol 2008; 104: 1313-1319.

9. Prentice AM. Manipulation of dietary fat and energy density and subsequent effects on substrate flux and food intake. Am J Clin Nutr 1998; 67: 535S-541S.

10. Moraes JC, Coope A, Morari J, Cintra DE, Roman EA, Pauli $\mathrm{JR}$, et al. High-fat diet induces apoptosis of hypothalamic neurons. PLoS One 2009; 4: e5045.

11. Pomplun D, Voigt A, Schulz TJ, Thierbach R, Pfeiffer AF, Ristow M. Reduced expression of mitochondrial frataxin in mice exacerbates diet-induced obesity. Proc Natl Acad Sci U S A 2007; 104: 6377-6381.

12. Wajchenberg BL. Subcutaneous and visceral adipose tissue: their relation to the metabolic syndrome. Endocr Rev 2000; 21: 697-738.

13. Stubbs RJ, Harbron CG, Murgatroyd PR, Prentice AM. Covert manipulation of dietary fat and energy density: effect on substrate flux and food intake in men eating ad libitum. Am J Clin Nutr 1995; 62: 316-329.

14. Delany C. Author's response. Aust J Physiother 2000; 46: 140.

15. Marette A, Geloen A, Collet A, Bukowiecki LJ. Defective metabolic effects of norepinephrine and insulin in obese Zucker rat brown adipose tissue. Am J Physiol 1990; 258: E320-E328.

16. Takeuchi H, Matsuo T, Tokuyama K, Shimomura Y, Suzuki $M$. Diet-induced thermogenesis is lower in rats fed a lard diet than in those fed a high oleic acid safflower oil diet, a safflower phenotypic factors leading to this disease.

\section{Acknowledgments}

The authors are very grateful to FAPESP for sponsoring their research.

oil diet or a linseed oil diet. J Nutr 1995; 125: 920-925

17. Shimomura Y, Tamura T, Suzuki M. Less body fat accumulation in rats fed a safflower oil diet than in rats fed a beef tallow diet. J Nutr 1990; 120: 1291-1296.

18. Liao FH, Liou TH, Chiu WC, Shieh MJ, Chien YW. Differential effects of high MUFA with high or low P/S ratio (polyunsaturated to saturated fatty acids) on improving hepatic lipolytic enzymes and mediating PPARgamma related with lipoprotein lipase and hormone-sensitive lipase of white adipose tissue in diet-induced obese hamster. Int J Obes 2010; 34: 16081617.

19. Matsuo T, Takeuchi H, Suzuki H, Suzuki M. Body fat accumulation is greater in rats fed a beef tallow diet than in rats fed a safflower or soybean oil diet. Asia Pac J Clin Nutr 2002; 11: 302-308.

20. Oosterveer MH, van Dijk TH, Tietge UJ, Boer T, Havinga R, Stellaard F, et al. High fat feeding induces hepatic fatty acid elongation in mice. PLoS One 2009; 4: e6066.

21. Rokling-Andersen MH, Rustan AC, Wensaas AJ, Kaalhus O, Wergedahl $\mathrm{H}$, Rost $\mathrm{TH}$, et al. Marine $\mathrm{n}-3$ fatty acids promote size reduction of visceral adipose depots, without altering body weight and composition, in male Wistar rats fed a highfat diet. Br J Nutr 2009; 102: 995-1006.

22. Matsuo T, Suzuki M. Beef tallow diet decreases lipoprotein lipase activities in brown adipose tissue, heart, and soleus muscle by reducing sympathetic activities in rats. J Nutr Sci Vitaminol 1994; 40: 569-581.

23. Awad AB, Zepp EA. Alteration of rat adipose tissue lipolytic response to norepinephrine by dietary fatty acid manipulation. Biochem Biophys Res Commun 1979; 86: 138-144.

24. Takeuchi H, Matsuo T, Tokuyama K, Suzuki M. Effect of dietary fat type on beta-oxidation of brown adipose tissue and $\mathrm{Na}^{+}$channel density of brain nerve membrane in rats. $J$ Nutr Sci Vitaminol 1996; 42: 161-166.

25. Siri-Tarino PW, Sun Q, Hu FB, Krauss RM. Saturated fat, carbohydrate, and cardiovascular disease. Am J Clin Nutr 2010; 91: 502-509.

26. Li JJ, Huang CJ, Xie D. Anti-obesity effects of conjugated linoleic acid, docosahexaenoic acid, and eicosapentaenoic acid. Mol Nutr Food Res 2008; 52: 631-645.

27. Harrington WW, Britt S, Wilson G, Milliken O, Binz G, Lobe $\mathrm{C}$, et al. The Effect of PPARalpha, PPARdelta, PPARgamma, and PPARpan Agonists on Body Weight, Body Mass, and Serum Lipid Profiles in Diet-Induced Obese AKR/J Mice. PPAR Res 2007; 2007: 97125.

28. Patsouris D, Muller M, Kersten S. Peroxisome proliferator activated receptor ligands for the treatment of insulin resistance. Curr Opin Investig Drugs 2004; 5: 1045-1050.

29. Yeop HC, Kargi AY, Omer M, Chan CK, Wabitsch M, O'Brien 
$K D$, et al. Differential effect of saturated and unsaturated free fatty acids on the generation of monocyte adhesion and chemotactic factors by adipocytes: dissociation of adipocyte hypertrophy from inflammation. Diabetes 2010; 59: 386396.

30. Flachs P, Horakova O, Brauner P, Rossmeisl M, Pecina P, Franssen-van $\mathrm{HN}$, et al. Polyunsaturated fatty acids of marine origin upregulate mitochondrial biogenesis and induce betaoxidation in white fat. Diabetologia 2005; 48: 2365-2375.

31. Motawi TM, Hashem RM, Rashed LA, El-Razek SM. Comparative study between the effect of the peroxisome proliferator activated receptor-alpha ligands fenofibrate and n-3 polyunsaturated fatty acids on activation of 5'-AMP-activated protein kinase-alpha1 in high-fat fed rats. J Pharm Pharmacol 2009; 61: 1339-1346.

32. Morgado N, Rigotti A, Valenzuela A. Comparative effect of fish oil feeding and other dietary fatty acids on plasma lipoproteins, biliary lipids, and hepatic expression of proteins involved in reverse cholesterol transport in the rat. Ann Nutr Metab 2005; 49: 397-406.

33. Montoya MT, Porres A, Serrano S, Fruchart JC, Mata P, Gerique $\mathrm{JA}$, et al. Fatty acid saturation of the diet and plasma lipid concentrations, lipoprotein particle concentrations, and cholesterol efflux capacity. Am J Clin Nutr 2002; 75: 484491.

34. Binkoski AE, Kris-Etherton PM, Wilson TA, Mountain ML, Nicolosi RJ. Balance of unsaturated fatty acids is important to a cholesterol-lowering diet: comparison of mid-oleic sunflower oil and olive oil on cardiovascular disease risk factors. J Am Diet Assoc 2005; 105: 1080-1086.

35. van Dijk SJ, Feskens EJ, Bos MB, Hoelen DW, Heijligenberg $\mathrm{R}$, Bromhaar MG, et al. A saturated fatty acid-rich diet induces an obesity-linked proinflammatory gene expression profile in adipose tissue of subjects at risk of metabolic syndrome. Am $J$ Clin Nutr 2009; 90: 1656-1664.

36. Paniagua JA, de la Sacristana AG, Sanchez E, Romero I, Vidal-Puig A, Berral FJ, et al. A MUFA-rich diet improves posprandial glucose, lipid and GLP-1 responses in insulinresistant subjects. J Am Coll Nutr 2007; 26: 434-444.

37. Jenkins DJ, Chiavaroli L, Wong JM, Kendall C, Lewis GF, Vidgen $\mathrm{E}$, et al. Adding monounsaturated fatty acids to a dietary portfolio of cholesterol-lowering foods in hypercholesterolemia. CMAJ 2010; 182: 1961-1967.

38. Storlien LH, Hulbert AJ, Else PL. Polyunsaturated fatty acids, membrane function and metabolic diseases such as diabetes and obesity. Curr Opin Clin Nutr Metab Care 1998; 1: 559563.

39. Vessby B. Dietary fat and insulin action in humans. Br J Nutr 2000; 83 (Suppl 1): S91-S96.

40. Unger RH, Scherer PE. Gluttony, sloth and the metabolic syndrome: a roadmap to lipotoxicity. Trends Endocrinol Metab 2010; 21: 345-352.

41. Muhlhausler B, Smith SR. Early-life origins of metabolic dysfunction: role of the adipocyte. Trends Endocrinol Metab 2009; 20: 51-57.

42. Storlien LH, Pan DA, Kriketos AD, O'Connor J, Caterson ID, Cooney GJ, et al. Skeletal muscle membrane lipids and insulin resistance. Lipids 1996; 31 (Suppl): S261-S265.

43. Feskens EJ, Kromhout D. Hyperinsulinemia, risk factors, and coronary heart disease. The Zutphen Elderly Study. Arterioscler Thromb 1994; 14: 1641-1647.

44. Storlien LH, Jenkins AB, Chisholm DJ, Pascoe WS, Khouri S,
Kraegen EW. Influence of dietary fat composition on development of insulin resistance in rats. Relationship to muscle triglyceride and omega- 3 fatty acids in muscle phospholipid. Diabetes 1991; 40: 280-289.

45. Storlien LH, Higgins JA, Thomas TC, Brown MA, Wang HQ, Huang XF, et al. Diet composition and insulin action in animal models. Br J Nutr 2000; 83 (Suppl 1): S85-S90.

46. Takahashi $Y$, Ide T. Dietary $n-3$ fatty acids affect mRNA level of brown adipose tissue uncoupling protein 1 , and white adipose tissue leptin and glucose transporter 4 in the rat. $\mathrm{Br} \mathrm{J} \mathrm{Nutr}$ 2000; 84: 175-184.

47. Lichtenstein $\mathrm{AH}$, Schwab US. Relationship of dietary fat to glucose metabolism. Atherosclerosis 2000; 150: 227-243.

48. Deutch B, Dyerberg J, Pedersen HS, Aschlund E, Hansen JC. Traditional and modern Greenlandic food - dietary composition, nutrients and contaminants. Sci Total Environ 2007; 384: 106-119.

49. Vessby B, Uusitupa M, Hermansen K, Riccardi G, Rivellese AA, Tapsell LC, et al. Substituting dietary saturated for monounsaturated fat impairs insulin sensitivity in healthy men and women: The KANWU Study. Diabetologia 2001; 44: 312319.

50. Friedman JM. Obesity: Causes and control of excess body fat. Nature 2009; 459: 340-342

51. Sial S, Coggan AR, Hickner RC, Klein S. Training-induced alterations in fat and carbohydrate metabolism during exercise in elderly subjects. Am J Physiol 1998; 274: E785-E790.

52. Donnelly JE, Blair SN, Jakicic JM, Manore MM, Rankin JW, Smith BK. American College of Sports Medicine Position Stand. Appropriate physical activity intervention strategies for weight loss and prevention of weight regain for adults. Med Sci Sports Exerc 2009; 41: 459-471.

53. Jakicic JM, Winters C, Lang W, Wing RR. Effects of intermittent exercise and use of home exercise equipment on adherence, weight loss, and fitness in overweight women: a randomized trial. JAMA 1999; 282: 1554-1560.

54. MacLean PS, Higgins JA, Wyatt HR, Melanson EL, Johnson GC, Jackman MR, et al. Regular exercise attenuates the metabolic drive to regain weight after long-term weight loss. Am J Physiol Regul Integr Comp Physiol 2009; 297: R793$\mathrm{R} 802$.

55. Goodpaster BH, He J, Watkins S, Kelley DE. Skeletal muscle lipid content and insulin resistance: evidence for a paradox in endurance-trained athletes. J Clin Endocrinol Metab 2001; 86: 5755-5761.

56. Boss A, Lecoultre V, Ruffieux C, Tappy L, Schneiter P. Combined effects of endurance training and dietary unsaturated fatty acids on physical performance, fat oxidation and insulin sensitivity. Br J Nutr 2010; 103: 1151-1159.

57. Mataix J, Quiles JL, Huertas JR, Battino M, Manas M. Tissue specific interactions of exercise, dietary fatty acids, and vitamin E in lipid peroxidation. Free Radic Biol Med 1998; 24 : 511-521.

58. Rogge MM. The role of impaired mitochondrial lipid oxidation in obesity. Biol Res Nurs 2009; 10: 356-373.

59. Kraegen EW, Cooney GJ, Turner N. Muscle insulin resistance: a case of fat overconsumption, not mitochondrial dysfunction. Proc Natl Acad Sci U S A 2008; 105: 7627-7628.

60. Muoio DM, Newgard CB. Mechanisms of disease: molecular and metabolic mechanisms of insulin resistance and beta-cell failure in type 2 diabetes. Nat Rev Mol Cell Biol 2008; 9: 193205. 